\title{
Effect of Environmental Factors on Pollen Viability of Tropical Trees in Garhjungle Sacred Forest Of West Bengal, India
}

\author{
*Ashoke Bhattacharya \\ Department of Botany Bidhannagar College EB-II, Sector - 1, Salt Lake Kolkata - 700 064, West Bengal, India \\ Corresponding Author: Ashoke Bhattacharya
}

\begin{abstract}
Tropical trees of Garhjungle sacred forest, West Bengal, India may change in pollen viability according to pollinator, flower exposure, and pollen predacious thrips. A pole clipper system was used, and in vitro viability measures, to evaluate relative impact of such factors in six forest tree species. Relative pollen viability was measured with Alexander's stain, or TTC stain for Madhuca indica Gmelin. (Sapotaceae); Buchanania lanzan Spreng. (Anacardiaceae); Pterocarpus marsupium Roxb. (Fabaceae); Alangium lamarckii Thw. (Alangiaceae); Schleichera oleosa (Lour.) Oken (Sapindaceae) and Tectona grandis Linn. (Verbenaceae). The impact of thrips was gauged from bagged and open flowers, and direct counts on flowers in Buchanania and Tectona; canopy position impact (affecting light, exposure, temperature) was gauged using collections made with pole clippers, and by reciprocal transfer of inflorescences on branches. Four native bee species were scored for viable pollen as they first left their nests in early morning. Viability decreased according to thrips presence in Buchanania and Tectona. The former had more thrips and significant damage only among lower flowers, while the latter showed most thrips damage on higher flowers. Pollen viability was higher on the higher flowers in Tectona, Madhuca, Buchanania, Pterocarpus, Alangium and Schleichera. Pollen viability in transplanted inflorescences changed in Tectona, Madhuca, Buchanania, Pterocarpus, Alangium and Schleichera. Viable pollen was recovered on native bees first leaving their nests in early morning, indicating prolonged pre-pollination potential. Various factors influence pollen viability in tropical field conditions. Thrips may effectively remove a large portion of pollen and exert more influence than physical exposure. Some flowers increase in pollen viability when exposed to gap conditions, but others show the opposite trend, with implications for degraded habitats. Bees may secondarily disperse viable pollen from their nests, in which it retains viability from one day to the next. Relative pollen viability was in agreement using different in vitro tests. Keywords: pollen, pollination, thrips, Garhjungle
\end{abstract}

\section{Introduction}

Before a pollen grain is released from an anther the environment may alter its germination capacity, and after release it may also undergo modification. Impacts of the floral environment and interacting organisms in this 'pre-pollination' phase of pollen biology have scarcely been investigated in the field (Brewbaker, 1967; Heslop-Harrison, 1986; Oni, 1990; Thomson and Thomson, 1992; Pacini et al, 1997). In situ exposure of pollen to thrips that feed on grain protoplasm causes damage before pollen is removed by pollinators (Kirk, 1985), while pollinators may futher modify pollen germination capacity (Kearns and Inouye, 1993; Hatjina et al, 1999). I investigated the potential impact of biotic and abiotic environmental factors; exposure and insolation, insect visitors or potential pollinators, and thrips within inflorescences to test their influence on pollen viability throughout the canopy in Garhjungle sacred forest, West Bengal, India.

\section{Materials And Methods}

The work has been carried out with six trees of economic importance, like Madhuca indica Gmelin. (Sapotaceae); Buchanania lanzan Spreng. (Anacardiaceae); Pterocarpus marsupium Roxb. (Fabaceae); Alangium lamarckii Thw. (Alangiaceae); Schleichera oleosa (Lour.) Oken (Sapindaceae) and Tectona grandis Linn. (Verbenaceae) growing in the forest. The study was conducted in Garhjungle forest located in Burdwan district of West Bengal, India extending between $23^{\circ} 40^{\prime} 54.4^{\prime \prime} \mathrm{N}$ latitude and $87^{\circ} 40^{\prime} 20.2^{\prime \prime} \mathrm{E}$ longitude. The altitude ranges from 65 to 68 meters above the sea level. This is a very old natural forest considered sacred among local people. This area is also known as the Dharma Garh of Raja Surath. It is believed to be one of the oldest places where Raja Surath was defeated by the Bhils and the Koals. But in the modern days, it was Jogiraj Bhahmananda Giri of the Dasami cult, who revived the place and once again started the Durga Puja during which thousands of devotees visit from nearby area. Despite being a sacred forest with traditional restrictions, Garhjungle experience various levels of anthropogenic disturbances such as extraction of fuel wood, collection 
of non timber forest produce, cattle grazing, and frequent human-caused fire. The climate of the study area is tropical. The temperature ranges from $34^{\circ} \mathrm{C}$ to $45^{\circ} \mathrm{C}$ in the summer and $8^{\circ} \mathrm{C}$ to $15^{\circ} \mathrm{C}$ in the winter. This area shows three distinct seasons - winter, summer and rainy throughout the year. Annual rainfall ranges from 120 to $150 \mathrm{~cm}$. Soil is red lateritic which is known for high level of iron content and poor in nutrient status. At different sites of the forest, the plants were sampled from the ground, using pole clippers of $10 \mathrm{~m}$ in length. Individual open flowers were collected by hand between 8,00 and 13,00 hours, directly stained with Alexander's stain and TTC stain in the field and the mounted slides were kept in plastic box until transported to the laboratory for observation under microscope. Up to five treatments were incorporated: (1) flowers collected in the exposed upper canopy (25-35 m) or in full sunlight; (2) flowers in shaded conditions, not at canopy height; (3) flowers that had been bagged to exclude thrips in the bud stage; (4) inflorescences on branches transferred from sun to shaded positions and (5) inflorescences transported from shade to exposed, sunny conditions. To minimize possible experimental bias introduced by weather or other variables, the displacement experiments were reciprocal, made in the morning between 0730 and 0900 hours, and the flowers were then collected between 1200 and 1300 hours. A branch with all inflorescences intact was removed and tied to a different position, including 20-30 cm of stem. When thrips were present on flowers, their abundance was evaluated by counting the insects in the plastic collection vials which held sample flowers. Ten flowers were collected for each sample of a particular inflorescence. For pollen viability studies on live bees, grains were collected on paper soda straws that were fixed in the bee nest entrance, thereby forcing bees to pass through them. The bee species employed were Apis dorsata; A. cerana indica, Tetragona dorsalis ziegleri and Plebeia franki and the solitary bee Centris analis (Apidae), all of which possess small, approximately bee-sized nest entrances. Straw tubes $2-3 \mathrm{~cm}$ in length were positioned at bee nest entrances before the first bees emerged, in early morning. The inside portion of the paper tube was then washed with Alexander's stain or TTC stain on a microscopic slide, then mounted and examined under a light microscope. Ten flowers from each sample were taken for preparing mounted slides subjected to Alexander's stain or TTC stain, using the same mix of pollen from flowers for both assays. Alexander's stain (Alexander, 1969) makes grains appear green when cytoplasm is absent. Although no correlation with germination (Marcellan and Camadro, 1996) was obtained using this stain but it can distinguish aborted from non-aborted pollen (Alexander, 1969). A modified staining reagent consisting of $0.5 \%$ solution of TTC in $20 \%$ sucrose was prepared. A drop of this solution was taken on microscope slide and pollens added, mounted immediately to exclude oxygen. The slides were kept for 3 hours, and then scored under microscope at 400X magnification following Dafni , 1992). Pollen grains stained red in presence of reductases, indicating the presence of active enzymes. These red grains were considered as viable. After three hours had elapsed, 100 grains were scored for pollen tube growth. Pollen grains were counted under a microscope at 400x, examining a total of 100 grains.

\section{Statistical analyses:}

The experiment was conducted following completely randomized design using at least three replications for each treatment. As random effects were followed, the data were analyzed for two-way analysis of variance (ANOVA, Model II) and test of significance $(\mathrm{P}<0.05)$ between each treatment. In order to determine the impact of Thrips on pollen viability of selected taxa, the independence of attributes in contingency table was tested using $\chi^{2}$ statistic. Mean values from all replicates were pooled and standard error of these values was calculated and pair-wise comparisons of all combinations with student's t-tests was made using SPSS software (SPSS Inc., USA).

\section{Results}

Pollen viability using Alexander's stain differed significantly among trees of each species and according to flower height and exposure (Table-1). The TTC stain tests confirmed the same trend. Significant differences occurred in pollen viability between different trees belonging to different species $(\mathrm{F}=5.975$, d.f. $=$ 29, 87; $\mathrm{P}<0.05)$ and exposure/ heights $(\mathrm{F}=4.284$, d.f. $=3,87 ; \mathrm{P}<0.05)$. Pollen registered lower viability in higher flowers of Pterocarpus marsupium but was significantly higher in the higher flowers in Tectona grandis, while no difference related to height or exposure was found for the four other species (Table-1). However, the Madhuca flowers did not display equivalent results according to the two viability tests (Table-1); no differences were revealed in TTC stain tests. The presence of many thrips in flowers of Tectona, Madhuca, Buchanania, Pterocarpus, Alangium and Schleichera markedly affected pollen viability and was not independent of flower position in the canopy (contingency table tests of flower height versus viability, $\chi^{2}=6.965$, df $=17, \mathrm{P}<.0001$ for all species). More thrips were associated with high flowers in Tectona, Madhuca and Buchanania with the opposite trend in Pterocarpus, Alangium and Schleicher. With few thrips present, compared to flowers with many thrips or with bagged inflorescences there was no relationship between flower height and pollen viability (contingency table tests, $\chi^{2}=4.115, \mathrm{df}=14, \mathrm{P}>0.1$ ). Therefore, the thrips had a greater impact than exposure 
or flower position, but there was no general trend in the position of flowers with more thrips damage. Pollen viability for Madhuca indica was $21 \%$ to $69 \%$ less according to Alexander's stain and TTC stain, respectively, in the presence of many thrips $(\mathrm{t}=4.13, \mathrm{df}=98, \mathrm{P}<0.001$ in Alexander's stain test and $\mathrm{t}=7.96, \mathrm{df}=72, \mathrm{P}<$ 0.001 in TTC stain test). Pollen viability was $59.6 \pm 4.04 \%$ through Alexander's stain and $14.5 \pm 1.9 \%$ through the TTC stain test, compared to $75.4 \pm 1.29 \%$ and $46.2 \pm 2.52 \%$, respectively, when thrips were excluded (Figs.-1 and 2). In Madhuca indica pollen damage from thrips in unbagged flowers indicated a $42 \%$ decrease by the Alexander's stain, but no comparisons were made using the TTC stain test. It is obtained $47.9 \pm 2.33 \%$ viable pollen from flowers exposed to some thrips (1-2 per flower) and $27.9 \pm 2.37 \%$ viable pollen from flowers exposed to several thrips. The percentage of viable pollens varied between species when flowers on branches were displaced to more insolated or shaded (high versus low) positions. Buchanania and Pterocarpus had no significant change in viability between branches that were transferred reciprocally (from low to high and from high to low positions). The viability of pollen in flowers of Madhuca indica increased when inflorescences were transferred from shaded to sunlight positions, while the opposite trend was noted in Tectona grandis. The pollen viability on bees exiting their nests was successfully scored for three of the four bee species. The solitary bee, Centris analis had a mean pollen viability of $33.3 \%$ of the grains sampled on two bees, similar to that on Apis dorsata and A. cerana indica $(36.26 \%, \mathrm{~N}=11)$. Both were higher than the $15.8 \%$ viable pollen on exiting foragers of the social bee Tetragona dorsalis $(\mathrm{N}=4)$. No viable pollen was detected, using either test, on the social bee Plebeia franki, and the TTC stain test did not show result in the samples from Apis dorsata and A. cerana indica, where $20.9 \%$ of grains produced a positive result (Table-2). A given plant species produces a given pollen morphotype and it has been found that two to seven different pollen morphotypes were associated with body surface of Apis dorsata and A. cerana indica followed by less frequency of pollen morphotype in Tetragona dorsalis, Centris analis and Plebeia franki respectively.

\section{Discussion}

After release from the anthers pollen grains are exposed to potentially hostile environments, such as dry or humid conditions, and yet they perform well and germinate to pollinate the stigma and fertilize the ovule in varied conditions (Heslop-Harrison, 1986). Thomson and Thomson (1992) have shown that pollen viability schedule deserve equal attention to pollen exposure schedules as an object of quantitative study for evolutionary ecologists. The pollen viability might be influenced by different factors like time of anthesis, temperature, humidity, seasonal effect, flower position, anther protection, age of pollen, pollinator type, pollen packaging, number of nucleus, carbohydrate content and desiccation risk, pollen metabolism and genetic variability (Dafni and Firmage, 2000). There are known limitations of trinucleate pollen viability that depend upon the elapsed time since anthesis (Brewbaker, 1967). As indicated by this author, with the possible exception of Tectona, the species we studied were binucleate. Assessment of pollen viability is critical for the study of pollination and gene flow in natural conditions (Shivanna et al, 1991; Dafni, 1992; Mulugeta et al, 1994; Dafni and Firmage, 2000). The term viability has been used to describe pollen grains capable of germinating on the stigma (Niesenbaum, 1992), germinating in vitro (Lindgren et al, 1995), taking up stains (Nyman, 1992), and causing fruit set (Smith-Huerta and Vasek, 1984). However, flower height in the canopy, heat and sunlight, and viability on pollinator bodies have seldom been considered for tropical trees in Garhjungle sacred forest of West Bengal. The present work shows the variations of pollen viability among different taxa investigated and is also dependent upon sunlight exposure, canopy position, presence of thrips and bee activity. The impact of such biotic and abiotic factors upon pollen viability of selected tropical trees in natural conditions might be reflected with regard to ecological implications upon pollen viability. The variations may be due to the desiccation factor, type of pollen exposure, pollinator behaviour and environmental factors. According to Pacini and Viegi (1995) and Speranza et al, (1997) the pollen viability is influenced by carbohydrate type and water content. Dafni and Firmage (2000) mentioned that the type of pollen exposure and pollinator behaviour impose as ecological factors and pose impacts upon pollen viability. Available literature suggests that pollen viability is often greater than $50 \%$ in laboratory conditions, depending on pollen age and taxon (Eisikowitch and Woodell, 1974; Sahar and Spiegel-Roy, 1984; Vasil, 1987; Steer and Steer, 1989; Demeke and Hughes, 1991; Aizen and Rovere, 1995), but still may vary widely between individual plants (Free and Williams, 1976; Oni, 1990).

This work suggests abiotic and biotic factors do determine the pollination potential of pollen in field conditions, that biotic factors may play a greater role than previously realized. As emphasized by author (Dafni, 1992) Alexander's stain does not demonstrate germination capacity but only that the pollen is intact. This was a convenient method for assay of damage caused by thrips which remove pollen contents. The results of both tests seemed conservative, particularly the low values found for TTC stain assay; failure of this technique with bees means that other assays should be attempted. The inconsistencies between the two methods showing a gap might be due to conservative appraisal of relative viability, in experimental tests and it is presumed that the two techniques provide a conservative evaluation. An optimal technique might employ sucrose solutions with boric acid (Brewbaker, 1967) that allow natural pollen tube growth to occur. 
The influence of thrips on pollen viability was demonstrated to have a pervasive influence, more than the physical variables included in shaded and exposed positions, in all species. It is unclear if there was active selection of higher or lower flowers where thrips concentrated, but pollen viability in the field cannot be studied without considering the location and abundance of thrips, which may vary within a tree, between individual trees, and between species of one tree genus. There is no explanation for the wide variation in pollen viability caused by inflorescence transfers to different conditions, but it is interesting that the two large trees, Tectona and Pterocarpus, each of which has small flowers with exposed anthers, responded in contrasting ways to heat, exposure and sunlight. High canopy flowers of Tectona produced pollen of higher viability, but the pollen in flowers transferred from low to high positions was reduced. In Madhuca indica, the position within the canopy in normal conditions did not influence pollen viability, but thrips damage was concentrated on higher flowers, thus pollen viability may tend, as in Tectona, to be higher in canopy flowers. Also, transfer of flowers to more exposed positions in the high canopy, in Madhuca indica, resulted in higher pollen viability. According to Thomson and Thomson (1992) and Dafni and Firmage (2000) the pollen viability becomes variable as influenced by flower/canopy position, light exposure and presence or absence of pollinators. Exposure is likely to become accentuated in converted or degraded tropical forests, or in forest gaps (Dixon et al, 1994; Johri and Vasil, 1961; Shivanna and Johri, 1989 and David, 1998) and the response of Madhuca indica would seem better adapted to such conditions.

\section{Conclusions}

Various environmental factors influence pollen viability in tropical forest tree species under field conditions of Garhjungle sacred forest of West Bengal. Thrips may effectively remove a large portion of pollen and exert more influence than physical exposure. Some flowers increase in pollen viability when exposed to gap conditions, but others show the opposite trend, with implications for degraded habitats. Bees may secondarily disperse viable pollen from their nests, in which it retains viability from one day to the next.

\section{Acknowledgements}

The author is thankful to the Principal of Bidhannagar College and Head of the Botany Department for providing laboratory facilities and to Mr. Aloke Biswas, Technical Staff, for technical support and sample collection during field survey to carry out this work and to UGC (ERO) for providing financial support in form of sanctioning the Minor Research Project No. F.PSW-184/15-16 (ERO).

\section{References}

[1] Aizen, M., Rovere A. 1995. Does pollen viability decrease with aging? A cross-population examination in Austrocedrus chilensis (Cupressaceae). International J. Plant Science 156, 227-231.

[2] Alexander, M,P. 1969. Differential staining of aborted and non-aborted pollen. Stain Technology 62, 107-112.

[3] Brewbaker, J.L. 1967. The distribution and phylogenetic significance of binucleate and trinucleate pollen grains in the angiosperms. American Journal of Botany 54, 1069-1083.

[4] Dafni, A. 1992. Pollination ecology: A practical approach. Oxford University Press, Oxford.

[5] Dafni, A., Firmage, D. 2000. Pollen viability and longevity: practical, ecological and evolutionary implications. Plant Syst. Evol. $222,113-132$.

[6] David, L. 1998. Large scale ecological restoration of degraded tropical forest lands: The potential role of timber plantations. Restoration Ecology 6, 271-279.

[7] Demeke, T., Hughes, H.G. 1991. Germination and storage of pollen of Phytolacca dodecandra L. (endod). Annals of Botany 68, 1315.

[8] Dixon, R.K., Brown, S., Houghton, R.A., Solomon, A.M., Trexler ,M.C., Wisniewski, J. 1994. Carbon pools and flux of global forest ecosystems. Science 263, 185-190.

[9] Eisikowitch. D., Woodell, S.R. 1974. The effect of water on pollen germination in two species of Primula. Evolution 28, 692-694.

[10] Free, J.B., Williams, I.H. 1976. Insect pollination of Anacardium occidentale L., Mangifera indica L., Blighia sapida Koenig and Persea americana Mill. Tropical Agriculture (Trinidad) 53, 125-139.

[11] Hatjina, F., Free, J.B., Paxton, R.J., 1999. Hive-entrance pollen transfer devices to increase the cross-pollination potential of honey bees. II. Examination of three materials and pollen viability. J. Apic. Research 38, 3-9.

[12] Heslop-Harrison, J.S. 1986. Pollen germination and pollen-tube growth. International Review of Cytology 107, 1-78.

[13] Johri, B.M., Vasil, I.K. 1961. Physiology of pollen. Botanical Review 27: 318-381 Kearns, C.A., Inouye, D.W. 1993. Techniques for pollination biologists. University Press of Colorado, Niwot, Colorado.

[14] Kirk, W.D.J. 1985. Pollen feeding and the host specificity and fecundity of flower thrips (Thysanoptera). Ecol. Entomol. 10, 281290.

[15] Lindgren, D., Paule, L., Xihuan, S., Yuazdani, R., Segerstorm, O., Wallin J-E, Lezbro, M.L. 1995. Can viable pollen carry Scots pine genes over long distances? Grana 34, 64-69.

[16] Marcellan, O.N., Camadro, E.L. 1996. The viability of Asparagus pollen after storage at low temperatures. Sci. Hort. 67, $101-104$.

[17] Mulugeta, D., Maxwell, B.D., Dyer, W.D. 1994. Kochia (Kochia scoparia) pollen dispersion, viability and germination. Weed Science 42, 548-552.

[18] Niesenbaum, R.A. 1992. Sex ratio, components of reproduction and pollen deposition in Lindera benzoin (Lauraceae). American Journal of Botany 79, 495-500.

[19] Nyman, I., 1992. Pollination mechanisms in six Campanula species (Campanulaceae). Plant Syst. Evol. 188, 97-108.

[20] Oni, O. 1990. Between-tree and floral variation in pollen viability and pollen tube growth in obeche (Triplochiton scleroxylon). Forest Ecology and Management 37, 259-265. 
[21] Pacini, E., Franchi, G.G., Lisci, M., Nepi, M., 1997. Pollen viability related to type of pollination in six angiosperm species. Annals of Botany 80, 83-87.

[22] Pacini, E., Viegi, L., 1995. Total polysaccharide content of developing pollen in two angiosperm species. Grana 39, 237 - 241.

[23] Sahar, N., Spiegel-Roy, P. 1984. In vitro germination of avocado pollen. Hort. Sci. 19, 886-888.

[24] Shivanna, K.R., Johri, B.M. 1989. The angiosperm pollen structure and function. Wiley Eastern Limited, New Delhi.

[25] Shivanna, K.R., Linskens, H.F., Cresti, C. 1991. Pollen viability and pollen vigor. Theor. Appl. Genet. 81, 38-42.

[26] Smith-Huerta, N.L., Vasek, F.C. 1984. Pollen longevity and stigma- pre-emption in Clarkia. American Journal of Botany 71, 11831191.

[27] Speranza, A., Calzoni, G.L., Pacini, E. 1997. Occurrence of mono- or disaccharides and polysaccharides reserve in mature pollen grain. Sexual Plant Reproduction 10, $110-115$.

[28] Steer, M.W., Steer, J.M. 1989. Pollen tube tip growth. New Phytol. 111, 323-358.

[29] Thomson, J.D. and Thomson, B. A. 1992. Pollen presentation and viability schedules in animal pollinated plants: consequences for reproductive success. In: Wyatt, R. (Ed.), Ecology and Evolution of Plant Reproduction: New approaches. Chapman and Hall, New York, pp. 1-24.

[30] Vasil, I. K. 1987. Physiology and culture of pollen. International Review of Cytology 107, 127-174.

Table 1: Pollen viability measured in Madhuca indica; Buchanania lanzan; Pterocarpus marsupium; Alangium lamarckii; Schleichera oleosa and Tectona grandis using Alexander's stain and TTC stain. Mean percentage, standard error and student's t-tests of differences between replicates at $\mathrm{P}<0.05$.

Pollen viability (\%)

\begin{tabular}{|c|c|c|c|c|}
\hline Plants' name & Canopy position & Alexander's stain & TTC stain & Significance* \\
\hline \multirow[t]{4}{*}{ Madhuca indica } & High canopy & $69.9 \pm 2.63, n=49$ & $42.3 \pm 3.09, n=46$ & \multirow{2}{*}{$\begin{array}{l}\mathrm{NS}, \mathrm{NS} \\
\mathrm{df}=74,62\end{array}$} \\
\hline & Low canopy & $73.5 \pm 3.15, n=27$ & $41.98 \pm 3.26, n=18$ & \\
\hline & Shifted- high to low & $79.4 \pm 1.79, n=25$ & $42.2 \pm 3.49, \mathrm{n}=22$ & \multirow{2}{*}{$\begin{array}{l}\mathrm{S}, \mathrm{S} \\
\mathrm{df}=36,30\end{array}$} \\
\hline & Shifted- low to high & $87.8 \pm 1.2, \mathrm{n}=13$ & $15.5 \pm 0.83, \mathrm{n}=10$ & \\
\hline \multirow[t]{4}{*}{ Buchanania lanzan } & High canopy & $37.9 \pm 2.57, n=20$ & $33.8 \pm 2.0, n=20$ & \multirow{2}{*}{$\begin{array}{l}\mathrm{S}, \mathrm{NS} \\
\mathrm{df}=42,42\end{array}$} \\
\hline & Low canopy & $46 \pm 2.48, n=24$ & $32.3 \pm 2.12, n=24$ & \\
\hline & Shifted-high to low & $62.9 \pm 2.27, n=10$ & $35.1 \pm 2.06, n=10$ & \multirow{2}{*}{$\begin{array}{l}\mathrm{NS}, \mathrm{S} \\
\mathrm{df}=18,18\end{array}$} \\
\hline & Shifted- low to high & $63.2 \pm 1.09, \mathrm{n}=10$ & $24.9 \pm 0.91, n=10$ & \\
\hline \multirow{4}{*}{$\begin{array}{l}\text { Pterocarpus } \\
\text { marsupium }\end{array}$} & High canopy & $78.2 \pm 1.32, \mathrm{n}=32$ & $29.9 \pm 0.87, \mathrm{n}=32$ & \multirow{2}{*}{$\begin{array}{l}\mathrm{S}, \mathrm{S} \\
\mathrm{df}=62,62\end{array}$} \\
\hline & Low canopy & $72.9 \pm 1.49, \mathrm{n}=32$ & $26.8 \pm 1.03, \mathrm{n}=32$ & \\
\hline & Switched-high- to- low & $69.8 \pm 2.02, n=18$ & $24.9 \pm 1.28, \mathrm{n}=18$ & \multirow{2}{*}{$\begin{array}{l}\mathrm{S}, \mathrm{S} \\
\mathrm{df}=33,33\end{array}$} \\
\hline & Switched-low- to- high & $52.7 \pm 2.56, \mathrm{n}=17$ & $16.1 \pm 1.32, \mathrm{n}=17$ & \\
\hline \multirow[t]{4}{*}{ Alangium lamarckii } & High canopy & $79.4 \pm 1.26, \mathrm{n}=16$ & $32.7 \pm 1.99, \mathrm{n}=16$ & \multirow{2}{*}{$\begin{array}{l}\mathrm{NS}, \mathrm{NS} \\
\mathrm{df}=30,30\end{array}$} \\
\hline & Low canopy & $77.9 \pm 1.14, \mathrm{n}=30$ & $30.6 \pm 1.03, \mathrm{n}=30$ & \\
\hline & Switched-high-to-low & $75.1 \pm 1.39, \mathrm{n}=16$ & $27.6 \pm 1.29, \mathrm{n}=16$ & \multirow{2}{*}{$\begin{array}{l}\mathrm{NS}, \mathrm{NS} \\
\mathrm{df}=29,29\end{array}$} \\
\hline & Switched-low-to-high & $70 \pm 2.15, n=15$ & $23.8 \pm 1.63, \mathrm{n}=15$ & \\
\hline \multirow[t]{4}{*}{ Schleichera oleosa } & High canopy & $71.9 \pm 2.73, n=39$ & $72.3 \pm 4.09, \mathrm{n}=36$ & \multirow{2}{*}{$\begin{array}{l}\mathrm{NS}, \mathrm{NS} \\
\mathrm{df}=74,62\end{array}$} \\
\hline & Low canopy & $71.5 \pm 3.15, \mathrm{n}=28$ & $71.98 \pm 2.22, \mathrm{n}=28$ & \\
\hline & Shifted- high to low & $70.4 \pm 2.19, \mathrm{n}=24$ & $62.2 \pm 2.48, \mathrm{n}=21$ & \multirow{2}{*}{$\begin{array}{l}\mathrm{S}, \mathrm{S} \\
\mathrm{df}=36,30\end{array}$} \\
\hline & Switched-low- to- high & $62.9 \pm 2.16, \mathrm{n}=18$ & $66.1 \pm 1.52, \mathrm{n}=18$ & \\
\hline \multirow[t]{4}{*}{ Tectona grandis } & High canopy & $75.2 \pm 1.72, n=32$ & $30.9 \pm 1.87, \mathrm{n}=32$ & \multirow{2}{*}{$\begin{array}{l}\text { S, S } \\
\mathrm{df}=62,62\end{array}$} \\
\hline & Low canopy & $74.9 \pm 1.79, \mathrm{n}=32$ & $36.8 \pm 1.03, \mathrm{n}=32$ & \\
\hline & Switched-high-to-low & $68.8 \pm 2.52, \mathrm{n}=18$ & $37.9 \pm 1.48, \mathrm{n}=18$ & \multirow{2}{*}{$\begin{array}{l}\mathrm{S}, \mathrm{S} \\
\mathrm{df}=33,33\end{array}$} \\
\hline & Switched-low-to-high & $58.5 \pm 2.22, \mathrm{n}=17$ & $25.1 \pm 1.82, n=17$ & \\
\hline
\end{tabular}

* comparisons of high to low (exposed to shaded) conditions or reciprocally shifted positions

Table 2: Pollen viability along the body surface of exiting bees from nest in early morning. Pollen morphotype is a species specific character and a given plant species produces a given pollen morphotype.

Viable pollen $(\%)$

\begin{tabular}{|l|l|l|l|}
\hline Bee species & Alexander's stain & TTC stain & Pollen morphotypes \\
\hline Apis dorsata & $36.26, \mathrm{n}=11$ & $20.9, \mathrm{n}=11$ & $2-7$ \\
\hline Apis cerana indica & $34.75, \mathrm{n}=14$ & $26.18, \mathrm{n}=10$ & $2-5$ \\
\hline Centris analis & $33.3, \mathrm{n}=2$ & - & 1 \\
\hline Plebeia franki & - & - & 1 \\
\hline Tetragona dorsalis & $15.8, \mathrm{n}=4$ & - & $1-2$ \\
\hline
\end{tabular}




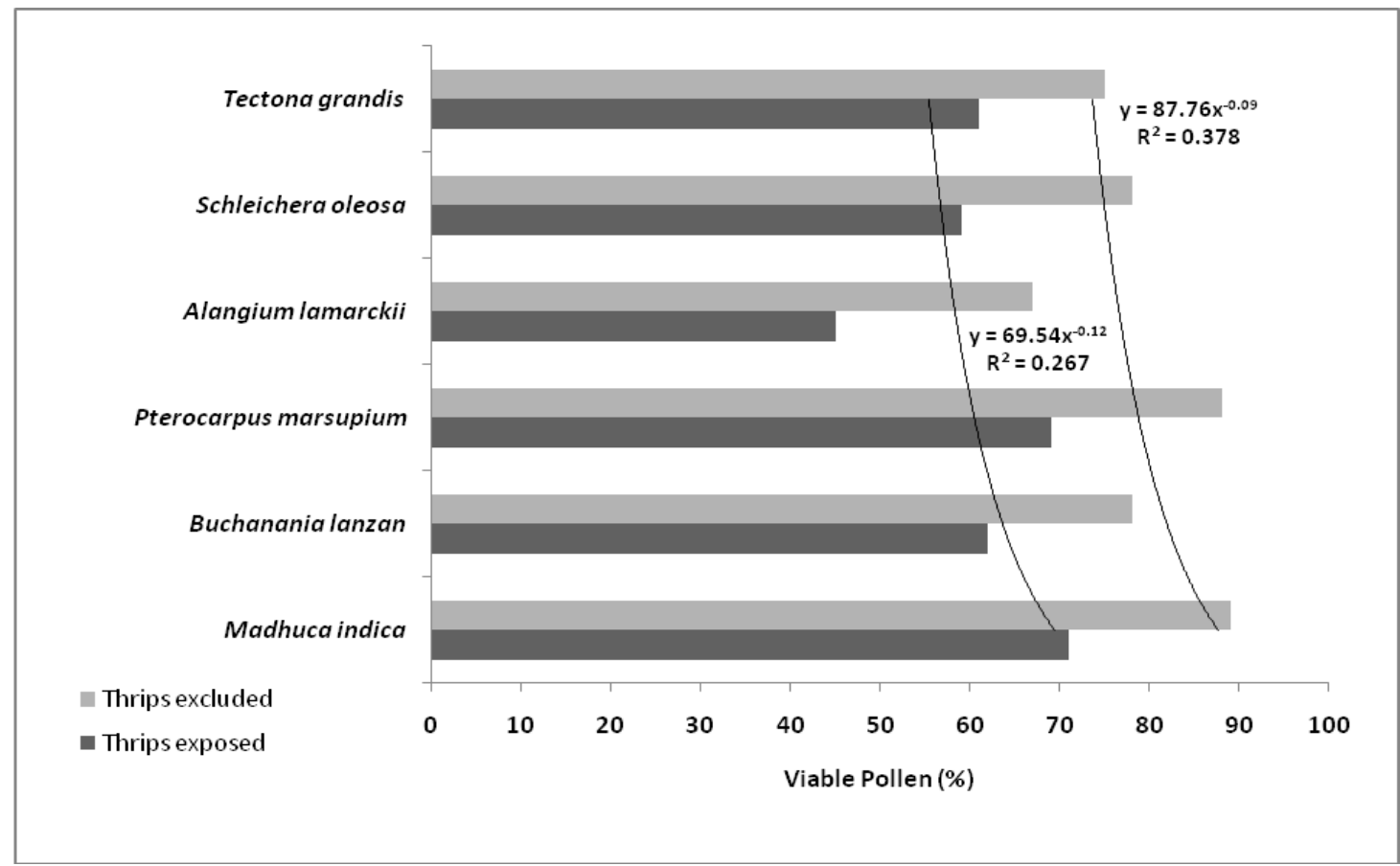

Fig. 1: Impact of Thrips exposure on pollen viability of selected taxa via Alexander's stain

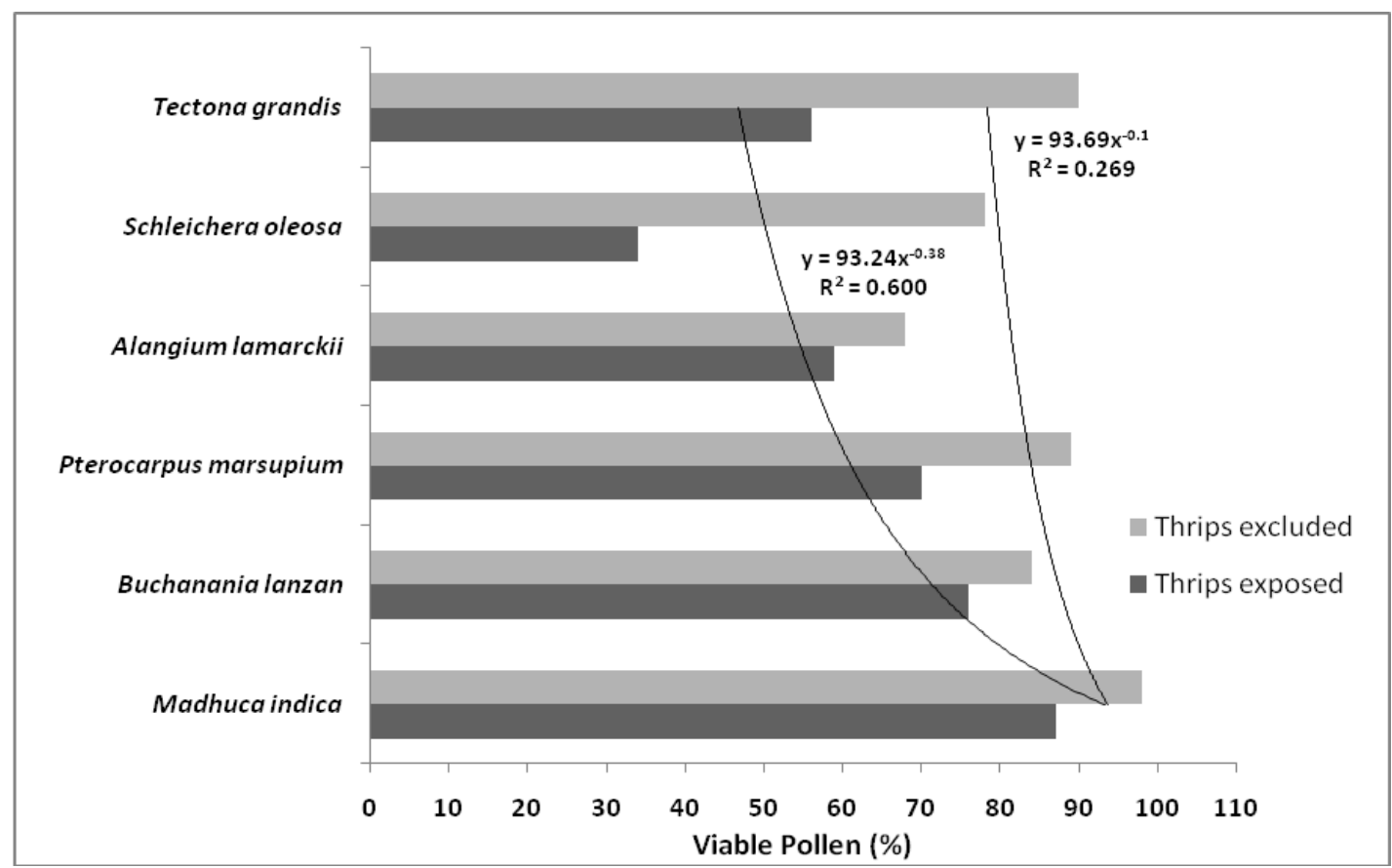

Fig. 2: Impact of Thrips exposure on pollen viability of selected taxa via TTC stain

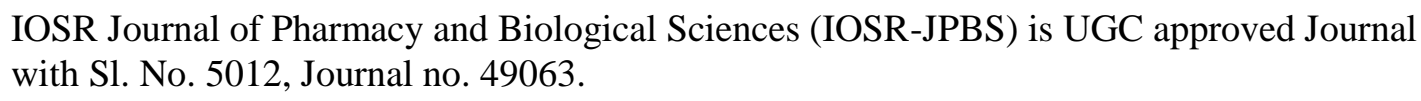

Ashoke Bhattacharya. "Effect of Environmental Factors on Pollen Viability of Tropical Trees in Garhjungle Sacred Forest Of West Bengal, India." IOSR Journal of Pharmacy and Biological Sciences (IOSR-JPBS) 12.4 (2017): 20-25. 